\title{
Basal cell nevus syndrome with excessive basal cell carcinomas
}

\author{
Choon Soo Kim, \\ Young Cheon Na \\ Department of Plastic and \\ Reconstructive Surgery, Wonkwang \\ University Hospital, Iksan, Korea
}

\begin{abstract}
Basal cell nevus syndrome (BCNS), also known as basal cell carcinoma nevus syndrome, Gorlin syndrome, Gorlin-Goltz syndrome, and nevoid basal cell carcinoma, is a rare autosomal dominant disorder with a prevalence of approximately $1 / 60,000$. A lower prevalence rate of 1/13,939,393 has also been reported in Korea. We report the case of a 40-year-old male patient with multiple black pigmented macules on the face that first appeared when he was a teenager. His clinical features of jaw cysts, bifid ribs, and calcification of the falx cerebri were fitting within the criteria for the diagnosis of BCNS. We excised all suspected macules and sent permanent biopsy. Most of the histological examinations of the biopsy samples taken during surgical excision of the face masses showed basal cell carcinomas. Ten months after the surgery, the patient has remained free from symptoms and is undergoing follow-up observation.
\end{abstract}

Keywords: Basal cell carcinoma / Basal cell nevus syndrome / Gorlin syndrome

\section{INTRODUCTION}

Basal cell nevus syndrome (BCNS) is a rare disease inherited in an autosomal dominant manner. It is characterized by the development of early-onset basal cell carcinomas $[1,2]$. The pathogenesis of BCNS is primarily associated with mutations in the $P T C H 1$ gene and rarely associated with mutations in the suppressor of fused and $\mathrm{PTCH} 2$ genes $[3,4]$. The BCNS was first reported by Jarisch [5], who described a patient with multiple basal cell carcinomas in 1894. Gorlin and Goltz first defined this condition as an autosomal dominant syndrome, comprising the principal triad of basal cell carcinoma, jaw cysts, and bifid ribs $[5,6]$. The prevalence of BCNS ranges from $1 / 57,000$ to $1 / 256,000$ and has a male to female ratio of $1: 1$. It has a lower prevalence rate of one per 13.9 million in Korea

\section{Correspondence: Young Cheon Na}

Department of Plastic and Reconstructive Surgery, Wonkwang University Hospital, 895 Muwang-ro, Iksan 54538, Korea

E-mail: ycnadr@hanmail.net

This work was supported by Wonkwang University in 2020.

Received April 4, 2021 / Revised April 19, 2021 / Accepted April 19, 2021
[2,7-10]. In this case report, we described our experience with a patient who presented with basal cell carcinomas and was diagnosed with BCNS.

\section{CASE REPORT}

A 40-year-old man visited the hospital with multiple non-tender masses on his face present for a long time. According to the patient, the masses began to appear on his face and neck 25 years ago, and some were diagnosed as basal cell carcinoma. The mass was evaluated using computed tomography (CT) and positron emission tomography-CT, but the results were nonspecific. Therefore, we decided to perform surgical excision under the initial impression of multiple basal cell carcinomas. Under general anesthesia, 59 lesions were removed (Figs. 1, 2). Histology of the 59 lesions showed that all, except five lesions, tested positive for basal cell carcinoma.

Based on the biopsy results, we suspected a BCNS (Fig. 3). Therefore, the patient's family history, personal history, and radiographic examinations were reviewed. He had a history of 


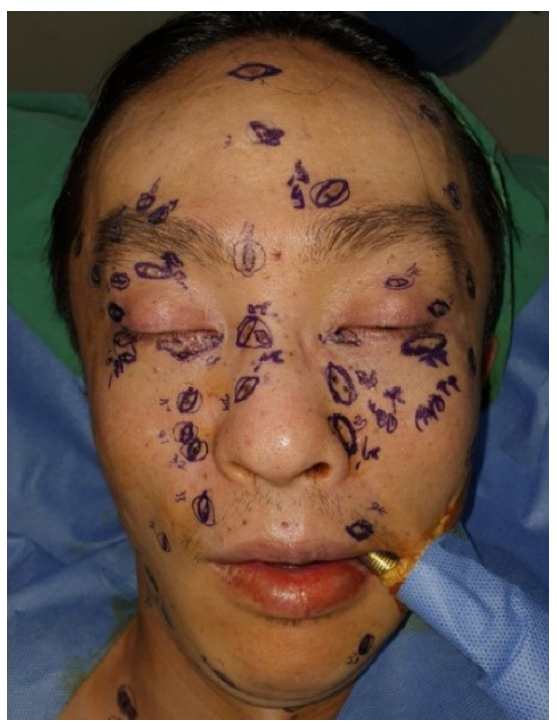

Fig. 1. Preoperative photograph showing the lines drawn along tumor margins for resection.

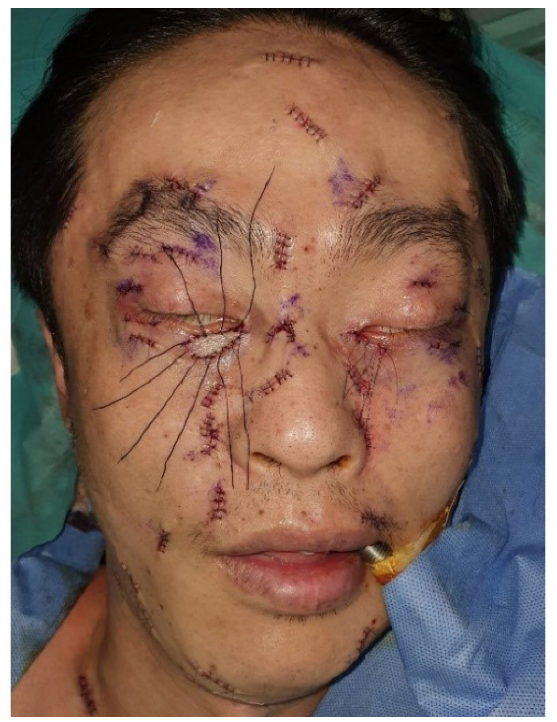

Fig. 2. Postoperative view. The defect of right medial lower eyelid was covered with a full-thickness skin graft harvested from right postauricular area and the remaining areas were primarily sutured.

excisional surgery for his jaw cyst, which was diagnosed as an odontogenic keratocyst when he was 19 years old. The suspected odontogenic cyst was identified through a panoramic view (Fig. 4). A bifid left sixth rib was observed on the anteroposterior view of the chest radiograph (Fig. 5), and brain CT revealed extensive calcifications of the falx cerebri (Fig. 6). He was diagnosed with BCNS based on findings matching the diagnostic criteria for BCNS [11].

The postoperative course was uneventful, and there was no recurrence or complications during the 10-month follow-up period. Although we recommended genetic tests of the patient

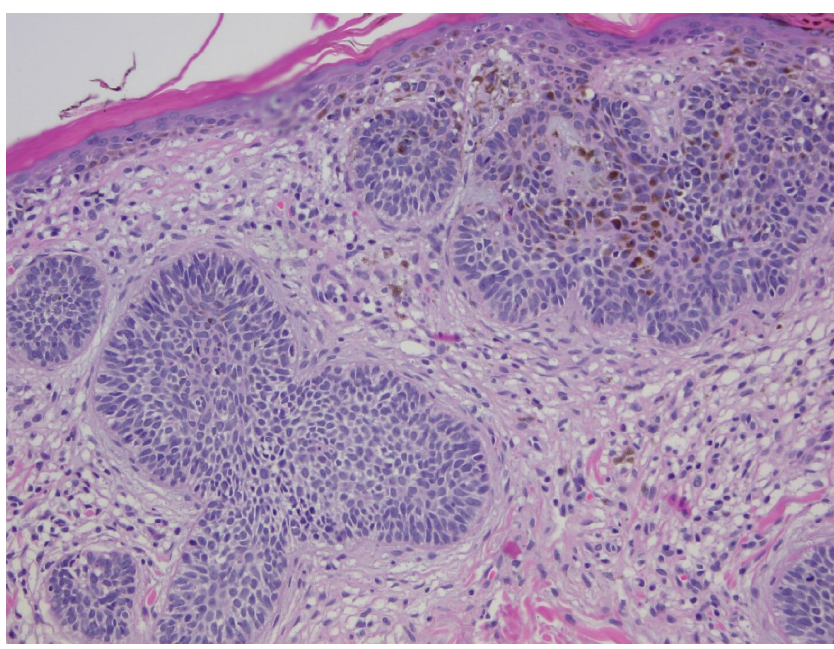

Fig. 3. Basal cell carcinoma: lobulated nests of neoplastic cells with retraction, palisaded basal layer $(\mathrm{H} \& \mathrm{E}, \times 200)$.

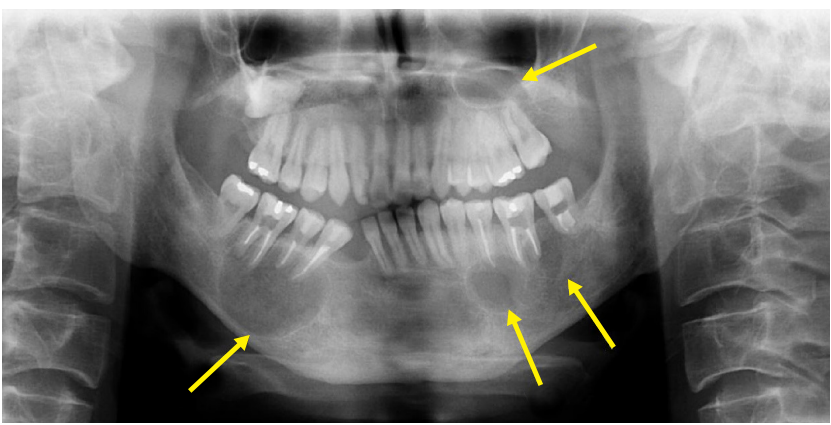

Fig. 4. Panoramic radiograph demonstrated multiple odontogenic cysts (yellow arrows) in the maxilla and mandible.

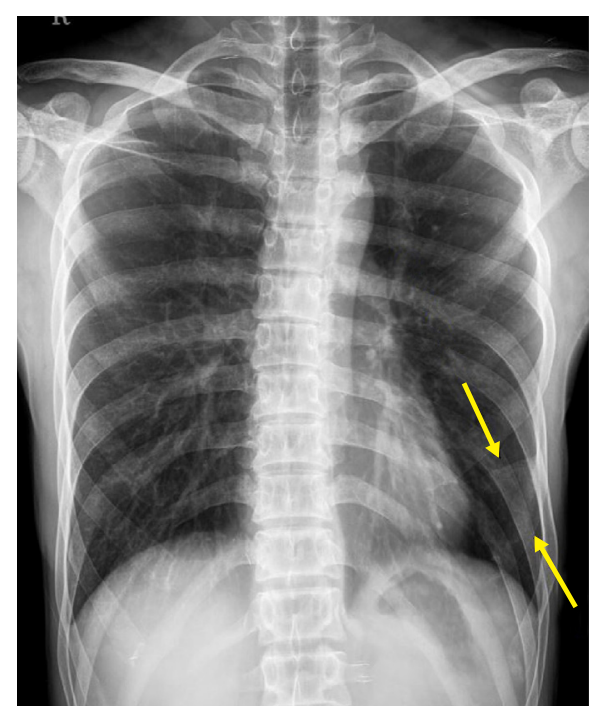

Fig. 5. Anteroposterior view of chest showing bifurcation of the left sixth rib (yellow arrows).

and his relatives for more comprehensive treatment, the patient and the relatives declined to do so. 


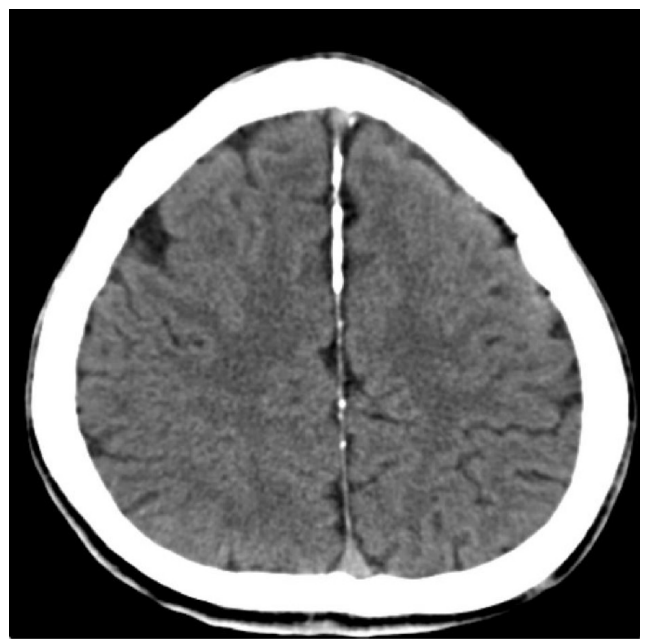

Fig. 6. Axial unenhanced computed tomography image of the brain revealed extensive calcifications of falx cerebri and tentorium cerebelli.

\section{DISCUSSION}

BCNS is a rare multisystemic disease inherited in an autosomal dominant condition with variable penetrance and its development was mainly associated with variations in the $P T C H 1$ gene [6,7]. PTCH1 regulates the growth of normal tissues and produces a tumor suppression factor [3].

The prevalence of BCNS is approximately one in 57,000 to one in 164,000 [1]. Men and women are equally affected [9]. In Korea, few cases of BCNS have been reported, and the reported prevalence of BCNS is approximately one in 13,939,393 [10].

$\mathrm{BCNS}$ is associated with different signs and symptoms. As the name suggests, the most common symptom of BCNS is the early development of basal cell carcinomas. While basal cell carcinomas are generally known to occur at over 60 years of age, basal cell carcinomas in BCNS are known to develop between puberty and 35 years of age $[3,12]$. Additional clinical features include odontogenic keratocysts, palmar and plantar pitting, frontal bossing, skeletal anomalies such as bifid ribs, Sprengel deformity, deformity of the pectus, polydactyly, syndactyly, hypertelorism, medulloblastoma or fibroma of ovaries, and lamellar calcification of the falx cerebri $[3,13]$. Since medulloblastoma can cause early death, BCNS patients must undergo immediate screening so they can be diagnosed promptly $[1,3]$.

Evans et al. first introduced the diagnostic criterion for BCNS, based on the most frequent and distinguishing clinical characteristics in 1993. This was updated in 1997 by Kimonis et al. [1] and in 2011 by Bree et al. [11]. These criteria have been continuously refined, but a final consensus has not been reached. In general, BCNS can be diagnosed if two major criteria or one major criterion and two minor criteria are met [3]. Recently, a new diagnostic condition of one major criterion with molecular confirmation has been introduced [11]. In our case, we were able to identify three major clinical features, including basal cell carcinomas, odontogenic keratocysts, and calcification of the falx cerebri. Bifid rib, which is a minor clinical symptom, was also observed. The patient was diagnosed with BCNS. The patient and his relatives declined to undergo genetic testing which was considered essential to obtain precise genetic confirmation.

The treatment of BCNS requires a multidisciplinary approach due to its various clinical manifestations. Although various treatments for BCNS have been suggested, no ideal treatment exists, and previous studies have focused on surgical excision using the standard or Mohs technique [13]. In our case, the basal cell carcinomas were managed with surgical excision by establishing appropriate surgical margins [14], and these did not recur during the observation period. However, periodic dermatologic examinations are necessary for BCNS patients to check for the possibility of recurrence.

In summary, BCNS is a rare disease that is difficult to diagnose and treat early. If suspected, various tests should be conducted at an early age, and accurate treatment is possible only when experts in various fields have adequate knowledge of BCNS. In addition, family members of patients diagnosed with BCNS should undergo genetic testing because of the genetic relevance of BCNS.

\section{NOTES}

\section{Conflict of interest}

No potential conflict of interest relevant to this article was reported.

\section{Ethical approval}

The study was approved by the Institutional Review Board of Wonkwang University Hospital (IRB No. WKUHIRB 2021-01024) and performed in accordance with the principles of the Declaration of Helsinki. Written informed consent was obtained.

\section{Patient consent}

The patient provided written informed consent for the publication and the use of his images.

\section{ORCID}

Choon Soo Kim https://orcid.org/0000-0003-2217-3175

Young Cheon Na 


\section{Author contribution}

Conceptualization: CSK. Project administration, visualization: YCN. Supervision: YCN. Writing - original draft: CSK. Writing - review \& editing: CSK, YCN.

\section{REFERENCES}

1. Kimonis VE, Goldstein AM, Pastakia B, Yang ML, Kase R, DiGiovanna JJ, et al. Clinical manifestations in 105 persons with nevoid basal cell carcinoma syndrome. Am J Med Genet 1997; 69:299-308.

2. Larsen AK, Mikkelsen DB, Hertz JM, Bygum A. Manifestations of Gorlin-Goltz syndrome. Dan Med J 2014;61:A4829.

3. Lo Muzio L. Nevoid basal cell carcinoma syndrome (Gorlin syndrome). Orphanet J Rare Dis 2008;3:32.

4. Fujii K, Ohashi H, Suzuki M, Hatsuse H, Shiohama T, Uchikawa $\mathrm{H}$, et al. Frameshift mutation in the PTCH2 gene can cause nevoid basal cell carcinoma syndrome. Fam Cancer 2013;12: 611-4.

5. Jarisch W. Zur lehre von den hautgeschwulsten. Archiv Dermatol Syph 1894;28:163-222.

6. Gorlin RJ, Goltz RW. Multiple nevoid basal-cell epithelioma, jaw cysts and bifid rib: a syndrome. N Engl J Med 1960;262: 908-12.
7. Farndon PA, Del Mastro RG, Evans DG, Kilpatrick MW. Location of gene for Gorlin syndrome. Lancet 1992;339:581-2.

8. Gorlin RJ. Nevoid basal cell carcinoma (Gorlin) syndrome: unanswered issues. J Lab Clin Med 1999;134:551-2.

9. Evans DG, Ladusans EJ, Rimmer S, Burnell LD, Thakker N, Farndon PA. Complications of the naevoid basal cell carcinoma syndrome: results of a population based study. J Med Genet 1993;30:460-4.

10. Ahn SG, Lim YS, Kim DK, Kim SG, Lee SH, Yoon JH. Nevoid basal cell carcinoma syndrome: a retrospective analysis of 33 affected Korean individuals. Int J Oral Maxillofac Surg 2004;33: 458-62.

11. Bree AF, Shah MR; BCNS Colloquium Group. Consensus statement from the first international colloquium on basal cell nevus syndrome (BCNS). Am J Med Genet A 2011;155A:2091-7.

12. Han SH, Kim SH, Kim CK, Jo DI. Multiple nonmelanocytic skin cancers in multiple regions. Arch Craniofac Surg 2020;21: 188-92.

13. Mitropoulos P, Norman R. Nevoid basal cell carcinoma syndrome (Gorlin syndrome): updated review of minimally invasive treatments. Cutis 2008;81:53-60.

14. Lee IS, Hong IP, Lee HK. Basal cell carcinoma and squamous cell carcinoma in a single tumor in the anterior auricular area. Arch Craniofac Surg 2020;21:257-60. 